Submitted to Earth and Planetary Science Letters, April 7, 2004.

\title{
Cooling history of the Pacific lithosphere
}

\author{
Michael H. Ritzwoller, Nikolai M. Shapiro, \& Shi-Jie Zhong \\ Department of Physics, University of Colorado at Boulder, Boulder, CO 80309-0390 USA (email: \\ ritzwoller@ciei.colorado.edu)
}

\begin{abstract}
Plate tectonics is expressed most simply in oceanic plates where a thermal boundary layer or "lithosphere" forms as the plate cools during its journey away from mid-ocean ridges $(1,2)$. Based on a seismic model of the Pacific upper mantle inferred from a new compilation of seismic surface wave dispersion measurements, we show that, on average, the Pacific lithosphere has experienced a punctuated cooling history, cooling diffusively for its first $70 \mathrm{Ma}$ and then reheating in the Central Pacific between ages of 70 and 100 Ma predominantly at depths between 70 and $150 \mathrm{~km}$. From $100 \mathrm{Ma}$ to about $135 \mathrm{Ma}$, the processes of reheating are substantially weaker than in the Central Pacific. We show that thermal boundary layer instabilities (TBI) develop naturally as the plate cools and, with the right rheology, can explain the mean characteristics of the observed cooling history of the Pacific plate.
\end{abstract}

\section{Introduction}

Few observables directly constrain the thermal state of the oceanic lithosphere and the "asthenosphere" that lies beneath it. Seafloor topography and heat flow (3-5) have been most commonly used to infer oceanic mantle temperatures as these surface observables reflect the average temperature and the temperature gradient in the uppermost mantle. The lithosphere is believed to cool with age because of the deepening of the sea-floor and the reduction in heat flow away from the mid-ocean ridges, but these trends cease and topography becomes much more erratic by about 80 Ma. Seismic waves provide a more direct probe of mantle structures, and seismic models have recently revealed that the Central Pacific hosts several intriguing features, including anomalous asthenospheric radial anisotropy (6), changes in the strength and orientation of azimuthal anisotropy $(7,8)$, and the existence of upper mantle and transition zone anelastic anomalies (9). The application of seismic models to sub-oceanic lithospheric geothermometry, however, has been limited due to substantial uncertainties in the conversion from seismic velocities to temperatures and by poor station coverage across the Pacific seafloor which has reduced both lateral and, more significantly, 
vertical resolution. Both issues have been increasingly ameliorated in recent years due to the growth of the global seismic network and advances in the theory of thermoelasticity (10).

Surface waves provide the most uniform coverage of the Pacific lithosphere of all seismic waves and now densely sample most of the Pacific basin. Several previous surface wave studies of the Pacific have been performed on a variety of length scales (e.g., 6, 11-15) Based on a new data set of surface wave dispersion measurements, this study presents models of the shear velocity and temperature structure of the upper mantle beneath the entire Pacific. Two different parameterizations are used: a purely seismic parameterization (16) and a temperature parameterization which is based on a thermal model of the lithosphere and underlying asthenosphere (17). Our aim is to elucidate large-scale thermal structures, and we report and discuss the potential cause (or causes) of an age-dependent trend that we refer to as the punctuated cooling of the Pacific lithosphere.

Throughout the paper, results will be compared to the temperature profile expected for a diffusively cooling half-space, called the Half-Space Cooling or HSC model. Predictions from the HSC model are intended to represent age trends expected for purely diffusive cooling. Deviations from the model are, therefore, evidence for other physical processes which is our purpose to identify and illuminate. The vertical temperature profile of the HSC model (2) is the solution to the onedimensional thermal diffusion equation for an infinite half-space, which takes the same form as equation (1) in section 2. The error-function temperature profile for the HSC model continues infinitely with depth and explicitly does not include adiabatic heating. Several ad-hoc choices (e.g., $T_{m}$, the $Q$-model) in specifying the HSC model create uncertainty in the absolute level of temperatures and seismic velocities in the mantle. We will account for this in several figures by shifting the HSC predictions to fit the observations optimally between $10 \mathrm{Ma}$ and $60 \mathrm{Ma}$. This shift also approximately corrects for the effect of adiabatic heating.

In section 2, we discuss the inversion procedure based on both parameterizations and the interconversion between seismic shear velocity and temperature. In section 3 we show that the dispersion maps demonstrate an age-dependent deviation from the predictions from the HSC model. Sections 4 and 5 show that a similar deviation from the HSC model is manifest in shear velocity and temperature. We conclude with an argument that this deviation from diffusive cooling is evidence for the on-set of thermal boundary layer instabilities (TBI) across the Pacific at about 70 Ma and a two-phae cooling history of the Pacific lithosphere.

\section{Inversion Procedure}

The inversion for a radially anisotropic 3-D tomographic model of shear-wave velocity and temperature is performed in two steps. In the first step, we compiled a large new data set of broad-band 
group velocity measurements and produced Rayleigh and Love wave group velocity maps (18) on a $2^{\circ} \times 2^{\circ}$ grid across the Pacific from $18 \mathrm{sec}$ period to $200 \mathrm{sec}$ for Rayleigh waves and from $20 \mathrm{sec}$ to $150 \mathrm{sec}$ for Love waves. There are more than 200,000 measurement paths world-wide. We also constructed phase velocity maps using measurements compiled at Harvard $(6,19)$ and Utrecht $(8)$ Universities from $40 \mathrm{sec}$ to $150 \mathrm{sec}$ period. The great length of most wavepaths across the Pacific necessitates considering the path-length dependent spatial sensitivity of the surface waves in order to model wave-front healing and associated diffraction effects (18). An example of dispersion curves estimated for a location in the Central Pacific is shown in Figure 1a. The joint inversion of group and phase velocities yields better vertical resolution than either data type alone, providing unique information about the vertical variability of shear velocities in the uppermost mantle (16).

In the second step, the dispersion maps are used to construct a $3-\mathrm{D}$ model on a $2^{\circ} \times 2^{\circ}$ grid to $400 \mathrm{~km}$ depth based on two separate parameterizations: a seismic parameterization (16) and a temperature parameterization derived from a thermal model (17).

\subsection{Inversion Based on the Seismic Parameterization}

The seismic parameterization (16) consists of 14 unknowns, seven in the crust and seven in the mantle. The crust comprises three layers in which compressional $\left(V_{p}\right)$ and shear $\left(V_{s}\right)$ velocity are free variables as is crustal thickness; all seven crustal unknowns are perturbed from reference values taken from the model CRUST2.0 (G. Laske, personal communication, 2002). Isotropic mantle structure is parameterized with four radial cubic B-splines. The remaining three unknowns parameterize radial anisotropy. Because Rayleigh waves are predominantly sensitive to $V_{s v}$ and Love waves to $V_{s h}$, we have constraints on only two of the five elastic moduli that describe a transversely isotropic medium. The basis functions for radial anisotropy represent the bifurcation of $V_{s h}$ and $V_{s v}$ in the uppermost mantle to a depth of $220 \mathrm{~km}$ and are sufficiently flexible to accommodate the unusual anisotropy in the Central Pacific (6). The effective isotropic shear velocity, $V_{s}$, is defined as the average of the anisotropic velocities.

The inversion proceeds by Monte-Carlo sampling that walks randomly through a subspace of seismic model space defined by a-priori constraints and forms a Markov-chain similar to Brownian motion. At each point on the $2^{\circ} \times 2^{\circ}$ grid, an ensemble of acceptable vertical profiles emerges. The Monte-Carlo inversion estimates a range of seismic (and hence temperature) models at each depth so that only features that appear in every member of the ensemble of acceptable models are interpreted. We refer to these features as "persistent". When a single model is needed, we use the middle of the ensemble of acceptable models. 


\subsection{Inversion Based on the Temperature Parameterization}

The temperature parameterization (Fig. 1b) is based on a thermal model in which a thermally conductive layer (lithosphere) overlies a convective layer (asthenosphere) joined smoothly by a transition layer. The temperature profile within the conductive layer is described by the half-space cooling solution,

$$
T(z)=T_{s}+\left(T_{m}-T_{s}\right) \operatorname{erf}(z / 2 \sqrt{\kappa \tau})
$$

where $z$ is depth in the mantle, $T_{m}$ is initial mantle temperature fixed at $1300^{\circ} \mathrm{C}, T_{s}=0^{\circ} \mathrm{C}$ is the surface temperature, thermal diffusivity $\kappa=1 \times 10^{-6} \mathrm{~m}^{2} \mathrm{~s}^{-1}$, and $\tau$ is the "apparent thermal age" of the lithosphere. In the convective layer, the adiabatic temperature gradient $D_{a}=0.5^{\circ} \mathrm{C} / \mathrm{km}$ and the potential temperature $T_{p}$ describe the thermal state of the asthenosphere.

Two mantle unknowns in the temperature parameterization specify the thermal state of the oceanic upper mantle: $\tau$ in the lithosphere and $T_{p}$ in the underlying asthenosphere. The first unknown is the "apparent thermal age" of the lithosphere which is the age at which a conductively cooling half-space would approximately match the observed lithospheric temperature structure, and the second unknown is the "potential temperature" of the asthenosphere which is the upward continuation to the surface of asthenospheric temperatures following the mantle adiabatic gradient. These two unknowns replace the four $B$-splines in the seismic parameterization.

The Monte-Carlo inversion with the temperature parameterization initiates in temperature space where a trial thermal model is constructed and is converted to shear velocity in the mantle, then trial seismic crustal structures are introduced as well as mantle radial anisotropy similar to the generation of these features in the seismic parameterization. The temperature profiles that fit the seismic data acceptably for an appropriate subset of seismic crustal models and models of radial anisotropy define the ensemble of acceptable profiles in temperature space and are also combined with the crustal and radial anisotropic models to define the ensemble of acceptable models in seismic velocity space. An example of the ensemble of acceptable models in temperature and seismic velocity are shown in Figure $1 \mathrm{c}$ and $1 \mathrm{~d}$.

Interconversion between temperature and shear velocity is based on laboratory-measured thermoelastic properties of mantle minerals represented as partial derivatives of the elastic moduli with respect to temperature, pressure, and composition (10). The compositional model for the oceanic upper mantle includes $75 \%$ Olivine, $21 \%$ Orthopyroxene, $3.5 \%$ Clinopyroxene, and $0.5 \%$ Spinel with an Iron-to-Magnesium ratio of $10 \%(20)$. We compute shear velocity with the anelastic correction $(10,21)$ from an anharmonic shear velocity, $v_{\text {anel }}(P, T, \omega)=v(P, T)\left[1-\left(2 Q_{\mu}^{-1}(P, T, \omega) / \tan (\pi a / 2)\right)\right]$, using a temperature dependent $Q$-model, $Q_{\mu}(P, T, \omega)=A \omega^{a} \exp \left[a\left(H^{*}+P V^{*}\right) / R T\right]$, where $R$ is 
the gas constant and we set the exponent $a=0.15$, anelastic activation energy $H^{*}=500 \mathrm{~kJ} / \mathrm{mol}$, anelastic activation volume $V^{*}=2.0 \times 10^{-5} \mathrm{~m}^{3} / \mathrm{mol}$, and the amplitude $A=0.049$.

\section{Surface Wave Dispersion Maps}

Data coverage, expressed as path density of Rayleigh wave group velocities, is shown in Figure 2. Coverage is best at intermediate periods, and reduces particularly at very long periods. It is also considerably lower for Love waves than for Rayleigh waves, especially at periods above about $100 \mathrm{sec}$. Resolution is estimated using the method of Barmin et al. (22) modified for diffraction tomography (with spatially extended sensitivity kernels (18)). Results are shown in Figure 3. Resolution is defined as twice the standard deviation of a Gaussian fit to the resolution surface at each target location. Average resolution across the Pacific is about $600 \mathrm{~km}$ at $20 \mathrm{sec}, 720 \mathrm{~km}$ at 50 sec, $850 \mathrm{~km}$ at $100 \mathrm{sec}$, and $980 \mathrm{~km}$ at $150 \mathrm{sec}$ period.

Figure 4a-c shows several surface wave speed maps across the Pacific (18), referenced to the prediction for a diffusively cooling half-space (Half-Space Cooling or HSC model (2)). For lithospheric ages younger than about $70 \mathrm{Ma}$, there is good agreement on average between the observed surface wave speeds and those predicted from the HSC model. A systematic deviation from the surface wave speeds predicted from the HSC model appears in the Central Pacific at a lithospheric age of about $70 \mathrm{Ma}$. In particular, wave speeds are depressed relative to the HSC model prediction in a north-south band across the Central Pacific ranging from about 70 to $100 \mathrm{Ma}$ and, on average, remain lower than the speeds predicted by the HSC model in the Western Pacific. The details of this discrepancy depend on wave type and period. The observation of the discrepancy is robust to data subsetting, to changes in the the theory of wavefield sensitivity (ray versus diffraction tomography (18)), and to the simultaneous inversion for azimuthal anisotropy. Simulations show that resolving this feature requires a lateral resolution better than about $1200 \mathrm{~km}$.

\section{Shear Velocity and Temperature Structure of the Pacific Upper Mantle}

Observations of surface wave dispersion strongly constrain shear velocities which are related to temperatures in the uppermost mantle (10). We applied the methods described in section 2 to surface wave dispersion maps across the Pacific and estimated radially anisotropic (transverse isotropy with a radial symmetry axis) three dimensional (3-D) tomographic models of shear-wave speed in the Earth's upper mantle by a Monte-Carlo method (12) using both seismic and temperature parameterizations. We describe the results here and show that the principal inferences are similar from both parameterizations.

Figure 5a,b presents the 3-D shear-velocity model from the seismic parameterization at a depth 
of $100 \mathrm{~km}$ in the uppermost mantle. The general increase in shear-wave speed toward the western Pacific, as seen in Figure 5a, is consistent with the prediction from the HSC model. As Figure 5c shows, until about $70 \mathrm{Ma}$ the age trend of the shear velocities at $100 \mathrm{~km}$ depth is, on average, in remarkable agreement with the predictions from the HSC model. Reflecting the information in the wave speed maps, a systematic deviation from the HSC model develops in the Central Pacific at lithospheric ages that range from about $70 \mathrm{Ma}$ to somewhat more than $100 \mathrm{Ma}$ (Fig. 5b-c). This deviation appears as a low shear-wave velocity anomaly running generally north-south in a crescent shaped feature across the Central Pacific, largely confined to the era between the $70 \mathrm{Ma}$ and 105 Ma age contours (Fig. 5b). The reduction of shear-wave speeds in this era is a persistent feature of the inversion.

Similar trends in seismic velocities and temperatures are revealed by both the seismic and thermal parameterizations (Fig. 6). Above and below $100 \mathrm{~km}$ depth, the deviation in shear velocity from the HSC model is similar to the pattern observed at $100 \mathrm{~km}$ but the amplitude decreases (Fig. 6d,e). As seen in Figure 7a, the average Pacific isotachs deepen with lithospheric age, following the HSC model until about $70 \mathrm{Ma}$ and then flatten until about $105 \mathrm{Ma}$, after which they deepen again. This deviation is shown in Figure $7 \mathrm{~b}$ to set-on abruptly at about $70 \mathrm{Ma}$ and maximizes in the deep lithosphere and shallow asthenosphere at depths between $70 \mathrm{~km}$ and $150 \mathrm{~km}$. The approximately uniform deviation deeper than $100 \mathrm{~km}$ is caused by the fact that the HSC reference model does not include adiabatic heating with depth.

The same trend with lithospheric age is revealed in the temperature structure seen in Figures 8-10. Lithospheric temperatures are summarized by the estimated apparent thermal age, shown in Figure 8. With the thermal parameterization, thermal age is a directly estimated variable but we also estimate thermal age from the seismic parameterization by converting $V_{s}$ to temperature and fitting the thermal model shown in Figure $1 \mathrm{~b}$ to the temperature profile. For both parameterizations we estimate a range of apparent thermal ages $(\tau)$ and potential temperatures $\left(T_{p}\right)$. We use the middle of the ensemble to construct Figures 8-10. Figures 8 and 9 show that the principal age trends in temperature are similar for the seismic and thermal parameterizations.

The apparent thermal age diverges systematically from the lithospheric age at about $70 \mathrm{Ma}$ and remains depressed throughout most of the old Pacific (Fig. 8c,e). The deficit in apparent lithospheric age that develops in the Central Pacific, referred to elsewhere as thermal resetting or extent of rejuvenation (5), is seen in Figure 9 to grow until it reaches more than 30 million years at a lithospheric age of 100 Ma. After this age, the age deficit is approximately constant, on average, but becomes highly variable in the very old Pacific at lithospheric ages greater than about 135 Ma. In terms of temperatures, average Pacific isotherms deepen with lithospheric age, as Figure 
10 shows, agreeing with the HSC model until about 70 Ma where they flatten until about 100 Ma and deepen again until about 135 Ma. By 100 Ma, average temperatures in the Pacific lithosphere at $100 \mathrm{~km}$ depth deviate from the temperatures of the $\mathrm{HSC}$ model by more than $100^{\circ} \mathrm{C}$.

\section{Discussion}

\subsection{Punctuated Cooling History of the Pacific Lithosphere}

Our results demonstrate that the seismic and thermal structures of the Pacific lithosphere deviate systematically from a model whose heat flux is dominated by diffusive cooling alone. Is this phenomenon the result of processes that are occurring now or the residual of processes that occurred in the past. Although temperatures of formation may have been higher between $70 \mathrm{Ma}$ and $100 \mathrm{Ma}$ than they were prior or subsequent to this era (23), the temperature anomalies observed in Figure 10 are probably too large to be the residual of elevated temperatures of formation. In addition, if surface heat flux were higher throughout the globe in this era, one would expect to observe elevated lithospheric temperatures beneath other ocean. In fact, we do not find elevated average temperatures during this era in other oceans as Figure 11 shows. The isotherms in Figure 11 are not observed to flatten between 70-100 Ma, in contrast with the temperature structure of the Pacific lithosphere shown in Figure 10. The processes that reheat the lithosphere in the Central Pacific have not affected the lithosphere beneath other oceans similarly, at least not in the age range between 70-100 Ma.

For these reasons, we conclude that the processes that have reheated the lithosphere are likely to be on-going and are unique to the Pacific. The age trend of lithospheric structure, therefore, suggests two phases of Pacific lithospheric cooling, from 0 Ma to $70 \mathrm{Ma}$ and another from $100 \mathrm{Ma}$ to 135 Ma, bracketing an era of lithospheric reheating during which an average thermal resetting of more than $30 \mathrm{Ma}$ develops. At ages older than $135 \mathrm{Ma}$, the thermal state of the lithosphere is highly variable and the statistics of inference are less favorable as the area covered by old lithosphere is small.

The reheating of the Pacific upper mantle has been proposed previously based largely on surface observables, such as seafloor topography and heat flow evidence (5). Various convective processes have been hypothesized as the cause of lithospheric reheating, including those confined to the upper mantle (e.g., small-scale convection directly beneath the lithosphere (24-26) or larger scale convection across the entire upper mantle (27)) and those that extend considerably deeper into the lower mantle (e.g. hot spot plumes $(28,29)$ or larger scale limbs of global convection possibly associated with superswells $(30,31))$. Near-surface structures, such as the accumulation of sediments (32), the formation of volcanic edifices (33), and associated crustal thickening, however, obscure 
the interpretation of surface observables alone, and our results provide the first direct evidence of the time-history (70 - $100 \mathrm{Ma})$ and depth extent $(70-150 \mathrm{~km})$ of reheating.

\subsection{Simulating Thermal Boundary Layer Instabilities (TBI)}

Recent seismic evidence points to a superplume that may heat the Central Pacific $(6,9)$, but the mechanics of heat transport from the upper mantle into the high viscosity lithosphere remain unclear. One possible mechanism is the development of thermal boundary layer instabilities (TBI), or small-scale convection, that remove the deep lithosphere and replace it with relatively hot asthenospheric material. The development of TBI may, indeed, be triggered and modulated by upwelling thermal plumes (34), but TBI also develops spontaneously without the influence of plumes as the lithosphere cools and thickens with age (24-26). Although the potential role of a thermal plume in the dynamics of TBI has been studied for the Hawaiian swell (34), superplumes at the Pacific plate scale are not well understood dynamically. For this reason, in order to examine the effects of TBI on lithospheric thermal structure we have simulated TBI without imposing thermal plumes. Convection cells formed as a result of TBI are too small to be imaged directly by our seismic model. Aspects of the larger-scale thermal anomalies apparent in the seismic model, however, may be caused by TBI. We discuss here only whether the consequences of TBI can match the average cooling history of the Pacific lithosphere, in particular lithospheric reheating that occurs in a discrete time interval from 70 to $100 \mathrm{Ma}$. We do not attempt to model or explain the considerable isochronous variability of the observed seismic and temperature structures.

Our 3-D Cartesian convection model uses a depth- and temperature-dependent Arrhenius rheology with flow-through boundary conditions (35). The model box is $1000 \mathrm{~km}$ deep, 12,000 km long (in the direction of plate motion), and $3,000 \mathrm{~km}$ wide. At the surface, temperature is $0^{\circ} \mathrm{C}$ and plate velocity is $5 \mathrm{~cm} /$ year, while at the bottom of the box temperature is $1350^{\circ} \mathrm{C}$ and velocity is zero. The inflow boundary has temperatures corresponding to $10 \mathrm{Ma}$ old lithosphere with velocities derived from a Couette flow. The outflow boundary has zero vertical temperature gradient and the same velocities as the inflow. The other two sidewalls (i.e., parallel to plate motion) have reflecting boundary conditions. The viscosity law is $\eta(z, T)=\eta_{0}(z) \exp (E / R T)$ where the pre-factor $\eta_{0}(z)$ is constant above $400 \mathrm{~km}$ depth and increases by a factor of 19 and 190 in the transition zone and lower mantle, respectively, compared with that in the upper mantle (36). The viscosity in the upper mantle is about $4 \times 10^{19} \mathrm{~Pa}$-s and rheological activation energy is $120 \mathrm{KJ} / \mathrm{mol}$. This leads to $\sim 70$ Ma onset time for TBI (36). This activation energy is consistent with that inferred from the study of flexural deformation near seamounts (37). Because we employ a Newtonian rheology, however, the activation energy may be viewed only as an "effective" rheological parameter for the mantle 
with a non-Newtonian rheology (38). The models are computed to a statistical steady-state. Other model parameters are thermal diffusivity of $10^{-6} \mathrm{~m}^{2} / \mathrm{s}$, coefficient of thermal expansion of $3 \times 10^{-5}$ $\mathrm{K}^{-1}$, mantle density of $3,300 \mathrm{~kg} / \mathrm{m}^{3}$, and gravitational acceleration equal to $9.8 \mathrm{~m} / \mathrm{s}^{2}$.

\subsection{Evidence for TBI}

Figure 12 shows the temperature profile from the 3-D convection simulation of thermal boundary layer instabilities (TBI) that is used to compute the thick solid line in Figure 13. The heating of the lithosphere by the TBI is seen in the divergence of the isotherms from the predictions of the HSC model. The difference between lithospheric thermal structure in the TBI simulation and the HSC model is shown in Figure 12b, illustrating how TBI heats the lithosphere and cools the asthenosphere.

Using a 3-D mantle convection model with temperature-dependent viscosity, the simulated TBI initiates when the lithosphere is $\sim 70$ Ma old, forms convective rolls oriented approximately along the direction of plate motion with characteristic diameters between $100-200 \mathrm{~km}$ (35), reheats the lithosphere to temperatures higher than in the HSC model $(26,36)$, and cools the asthenosphere. The onset time of TBI is controlled mainly by asthenospheric viscosity and activation energy $(26,36,39)$, but the temperature anomalies caused by TBI, which determine the extent of lithospheric reheating and its time evolution, depend dominantly on rheological activation energy $(26,36)$. Analogous to the seismic results, we quantify the extent of lithospheric reheating by estimating the apparent thermal age of the lithosphere from the simulated temperature structure. We find that, with a judicious choice of rheology, TBI can reheat the lithosphere to match the average cooling history of the Pacific lithosphere. As shown in Figure 13, after the onset of TBI, the apparent thermal age remains approximately constant for a period of $\sim 25 \mathrm{Ma}$ after which the apparent thermal age increases again. Although TBI remains active after $100 \mathrm{Ma}$, it is less vigorous because increases in asthenospheric viscosity caused by TBI at younger ages reduce asthenospheric temperatures (35). A good match between the simulated and observed cooling histories is achieved with an effective rheological activation energy of $120 \mathrm{~kJ} / \mathrm{mol}$. Because a Newtonian rheology has been used, this activation energy may be viewed only as an "effective" rheological parameter for the mantle with a non-Newtonian rheology (38).

If the reheating in the Central Pacific is caused by TBI, it is intriguing that reheating is not observed to be robust feature in other oceans. This fact requires further investigation, but it is not entirely unexpected for a convecting system with non-Newtonian rheology in which the vigor of the instabilities will depend on the speed of the plate. The current simulations are for a Newtonian rheology. Further simulations with a non-Newtonian rheology are needed to investigate this issue. 
Although TBI can explain the average cooling history of the Pacific lithosphere, our simulations do not explain the variation within lithospheric age ranges observed seismically. To explain this variability may require additional physical processes not included in the simulations presented here, such as variations in the conditions of formation of the lithosphere, the effects of thermal plumes, or non-Newtonian rheology. Plumes, in particular, are likely to play an important, but geographically variable, role in the onset and stabilization of TBI. 


\section{References}

1. McKenzie, D.P., Some remarks on heat flow and gravity anomalies, J. Geophys. Res., 72, 6261 (1967).

2. Parker, R.L. \& Oldenburg, D.W., Thermal model of ocean ridges, Nature Phys. Sci., 242, 137 (1973).

3. Parsons, B. \& Sclater, J.G., An analysis of the variation of ocean floor bathymetry and heat flow with age, J. Geophys. Res., 82, 803 (1977).

4. Stein, C. A. \& Stein, S., A model for the global variation in oceanic depth and heat flow with lithospheric age, Nature, 359, 123 (1992).

5. Nagihara, S., Lister, C.R.B., \& J.G. Sclater, Reheating of old oceanic lithosphere: Deductions from observations, Earth Planet. Sci. Letts., 139, 91 (1996).

6. Ekström, G. \& Dziewonski, A.M., The unique anisotropy of the Pacific upper mantle, Nature, 394, 168 (1998).

7. Ekström, G., Mapping the lithosphere and asthenosphere with surface waves: Lateral structure and anisotropy, in The History and Dynamics of Global Plate Motions, ed. M.A. Richards, R.G. Gordon, R.D. van der Hilst, Amer. Geophys. Un. Geophys. Monogr. 121, 239, Washington, D.C. (2000).

8. Trampert, J. \& Woodhouse, J.H., Global anisotropic phase velocity maps for fundamental mode surface waves between $40 \mathrm{~s}$ and $150 \mathrm{~s}$, Geophys. J. Int., 154, 154 (2003).

9. Romanowicz, B. \& Gung, Y., Superplumes from the core-mantle boundary to the lithosphere: Implications for heat flux, Science, 296, 513 (2002).

10. Goes, S., Govers, R., \& Vacher, R., Shallow mantle temperatures under Europe from P and S wave tomography, J. Geophys. Res., 105, 11,153 (2000).

11. Nishimura, C.E. and D.W. Forsyth, The anisotropic structure of the upper mantle in the Pacific, Geophys. J., 96, 203-229, 1989.

12. Forsyth, D.W., S.C. Webb, L.M. Dorman, and Y. Shen, Phase velocities of Rayleigh waves in the MELT experiment of the East Pacific Rise, Science, 280, 1235-1238, 1998.

13. Gaherty, J.B., M. Kato, and T.H. Jordan, Seismological structure of the upper mantle: a regional comparison of seismic layering, Phys. Earth Planet. Ints., 110, 21-41, 1999.

14. Zhang, Y.-S. and T. Lay, Evolution of oceanic upper mantle structure, Phys. Earth Planet. Ints, 114, 71-80, 1999.

15. Montagner, J.P., Upper mantle low anisotropy channels below the Pacific plate, Earth Planet. Sci. Letts., 202, 263-374, 2002.

16. Shapiro, N.M. \& Ritzwoller, M.H., Monte-Carlo inversion for a global shear velocity model of the crust and upper mantle, Geophys. J. Int., 51, 88 (2002). 
17. Shapiro, N.M. \& Ritzwoller, M.H., Thermodynamic constraints on seismic inversions, Geophys. J. Int., in press (2004).

18. Ritzwoller, M.H., Shapiro, N.M., Barmin, M.P., \& Levshin, A.L., Global surface wave diffraction tomography, J. Geophys. Res., 107(B12), 233 (2003).

19. Ekström, G., Tromp, J., \& Larson, E.W.F., Measurements and global models of surface waves propagation, J. Geophys. Res.102, 8137-8157, 1997.

20. McDonough, W.F. \& Rudnick, R.L., Mineralogy and composition of the upper mantle, in: Ultrahigh-pressure mineralogy: physics and chemistry of the Earth's deep interior, R.J. Hemley, Editor, 139, Mineralogical Society of America, Washington, DC, (1998).

21. Sobolev, S.V. et al., Zeyen, H., Stoll, G., Werling, F., Altherr, R., \& Fuchs, K., Upper mantle temperatures from teleseismic tomography of French Massif Central including effects of composition, mineral reactions, anharmonicity, anelasticity and partial melt. Earth Planet. Sci. Letts., 15\%, 193-207, 1996.

22. Barmin, M.P., M.H. Ritzwoller, and A.L. Levshin, A fast and reliable method for surface wave tomography, Phys. Earth Planet. Int., 158, 1351 - 1375, 2001.

23. Larson, R.L., Latest pulse of Earth: Evidence for a mid-Cretaceous superplume, Geology, 19, 547 (1991).

24. Richter, F. M. \& Parsons, B., On the interaction of two scales of convection in the mantle, J. Geophys. Res., 80, 2529 (1975).

25. Parsons, B. \& McKenzie, D., Mantle convection and thermal structure of the plates, J. Geophys. Res., 83, 4485 (1978).

26. Davaille, A. \& Jaupart, C., Onset of thermal convection in fluids with temperature-dependent viscosity: application to the oceanic lithosphere, J. Geophys. Res., 99, 19,853 (1994).

27. Houseman, G. \& McKenzie, D.P., Numerical experiments on the onset of convective instability in the Earth's mantle, Geophys. J. R. Astron. Soc., 68, 133 (1982).

28. Crough, S.T., Thermal origin of mid-plate hot-spot swells, Geophys. J. R. Astron. Soc., 55, 451 (1978).

29. Schroeder, W., The empirical age-depth relation and depth anomalies in the Pacific Ocean, J. Geophys. Res., 89, 9873 (1984).

30. McNutt, M.K., Superswells, Revs. Geophys., 36, 211 (1998).

31. Davaille, A., Simultaneous generation of hotspots and superswells by convection in a heterogeneous planetary mantle, Nature, 16, 756-760, 1999.

32. White, R.S., D. McKenzie, and R.K. O'Nions, Oceanic crustal thickness measurements and rare earth element inversions, J. Geophys. Res., 97, 19,683-19,715, 1992.

33. Coffin, M.F., and O. Eldholm, Large igneous provinces: crustal structure, dimensions, and external consequences, Revs. Geophys., 32, 1-36, 1994. 
34. Moore, W.B., Schubert, G. \& Tackley, P., Three-dimensional simulations of plume-lithosphere interaction at Hawaiian Swell, Science, 279, 1008 (1998).

35. van Hunen, J., Huang, J., \& Zhong, S., The effect of shearing on onset and vigor of small-scale convection with a Newtonian rheology, Geophys. Res. Lett., 30, 1991, doi:10.1029/2003GL018101 (2003).

36. Huang, J., Zhong, S. \& van Hunen, J. Controls on sub-lithospheric small-scale convection, J. Geophys. Res., 108, 2405, doi:10.1029/2003JB002456 (2003).

37. Watts, A.B. \& Zhong, S., Observations of flexure and the rheology of oceanic lithosphere, Geophys. J. Int., 142, 855 (2000).

38. Christensen, U. R., Convection with pressure and temperature dependent non-Newtonian rheology, Geophys. J. R. Astron. Soc., 77, 242 (1984).

39. Korenaga, J. \& Jordan, T. H., Physics of multiscale convection in Earth's mantle: Onset of sublithospheric convection, J. Geophys. Res., 108(B7), 2333 (2003).

40. Mueller, R.D., Roest, W.R., Royer, J.-Y., Gahagan, L.M., \& Sclater, J.G., Digital isochrons of the world's ocean floor, J. Geophys. Res., 102, 3211 (1997).

41. Trampert, J. \& Woodhouse, J.H., Global phase velocity maps of Love and Rayleigh waves between 40 and 150 s period, Geophys. J. Int., 122, 675 (1995). 
Acknowledgements. The data used in this work were obtained from the IRIS Data Management Center and the GEOSCOPE Data Center. The authors are grateful to researchers at Harvard $(6,19)$ and Utrecht $(8,41)$ Universities for contributing phase velocity measurements to this study. We are grateful for the help of Jeroen van Hunen with the modeling of thermal boundary layer instabilities. We thank Anatoli Levshin, William Landuyt, Rosa Bernal, Liz Zea, and Abir van Hunen for help in preparing the data set. We are grateful to Jeannot Trampert for a review of an early draft of the manuscript. Aspects of this work were supported by the US National Science Foundation and the Packard Foundation.

Correspondence and requests for materials should be addressed to M.H.R. (ritzwoller@ciei.colorado.edu) 
(a)

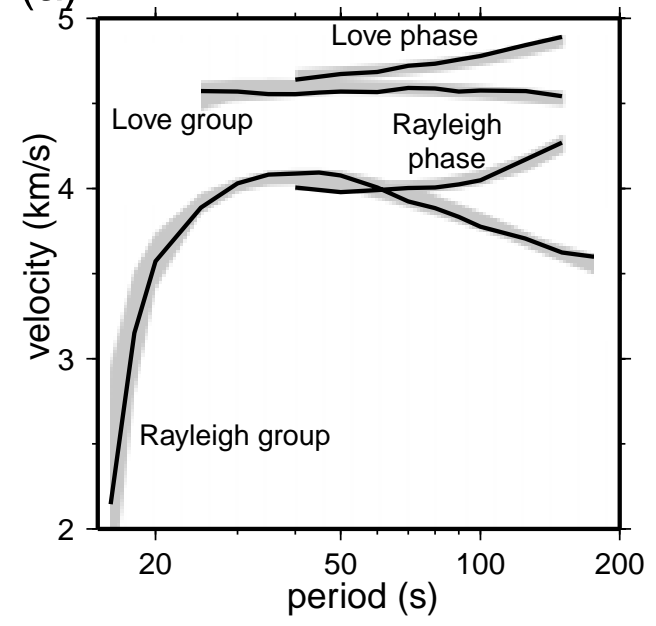

(c)

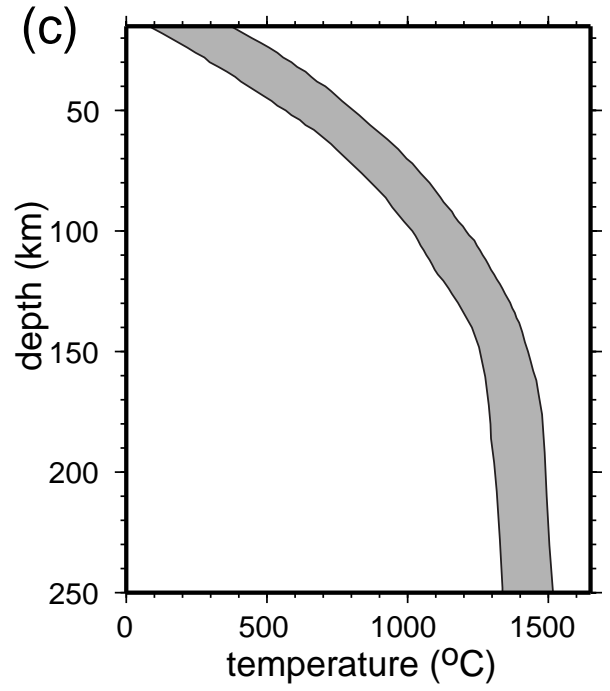

(b)
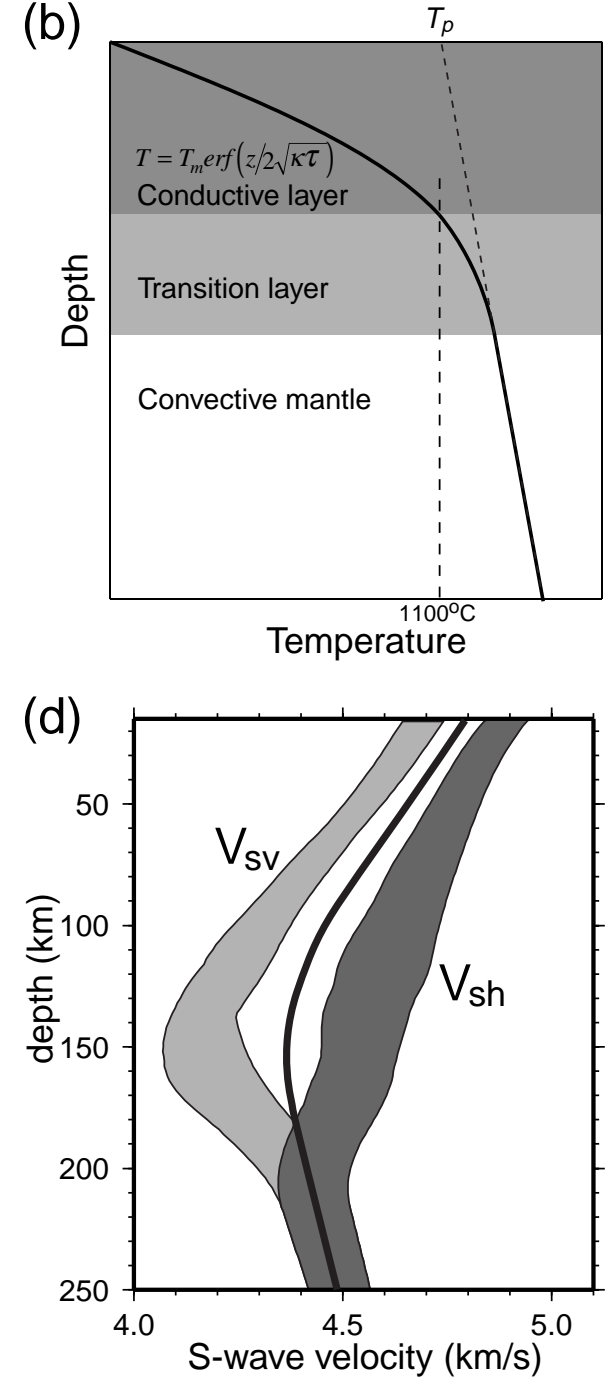

Figure 1: Construction of the 3-D model at a point in the Central Pacific using the thermal parameterization. (a) The four observed dispersion curves at a location in the Central Pacific $\left(14^{\circ} \mathrm{N}, 200^{\circ} \mathrm{E}\right)$ are plotted with black lines. (b) The temperature parameterization is based on a thermal model in which an error function, which represents temperatures in the lithosphere (eqn. 1), is underlain by an adiabatic gradient in the convective mantle (asthenosphere), joined smoothly by a transition region. The unknown in the conductive layer is the apparent thermal age, $\tau$, and the unknown in the underlying asthenosphere is the potential temperature, $T_{p}$. (c) \& (d) Inversion results for the Central Pacific location. The ensemble of acceptable temperature models in the uppermost mantle is shown in (c). The ensemble of seismic models is displayed in (d), where the light grey-shaded envelope is $V_{s v}$ and the dark grey-shaded envelope is $V_{s h}$. The thick black line is the median of the ensemble of isotropic shear velocities, $V_{s}$. This example demonstrates the unusual anisotropy in the Central Pacific (6) in which the bifurcation between $V_{s v}$ and $V_{s h}$ grows with depth, maximizing here at about $140 \mathrm{~km}$. Predictions from the ensemble of acceptable models to the four observed dispersion curves are shown as grey lines in (a). 
(a)

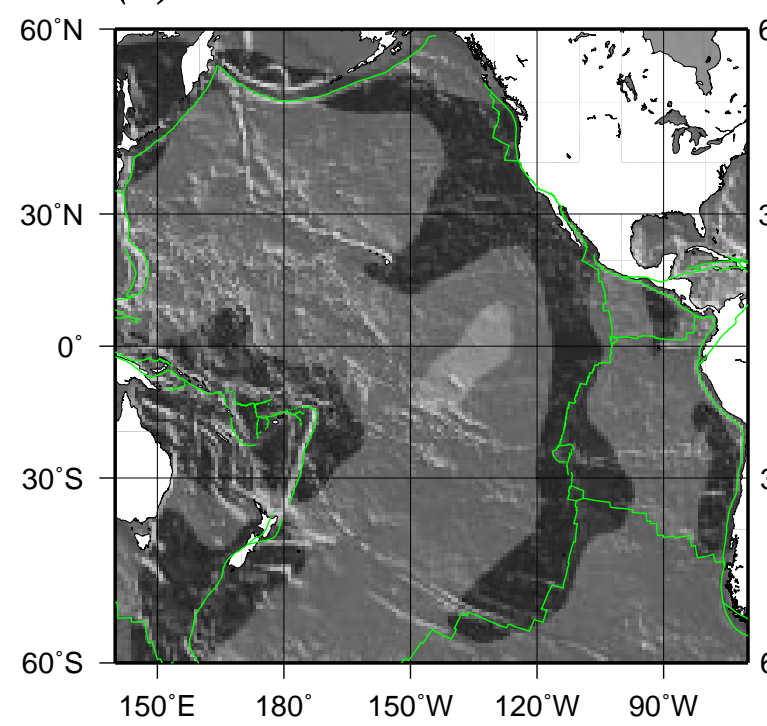

(c)

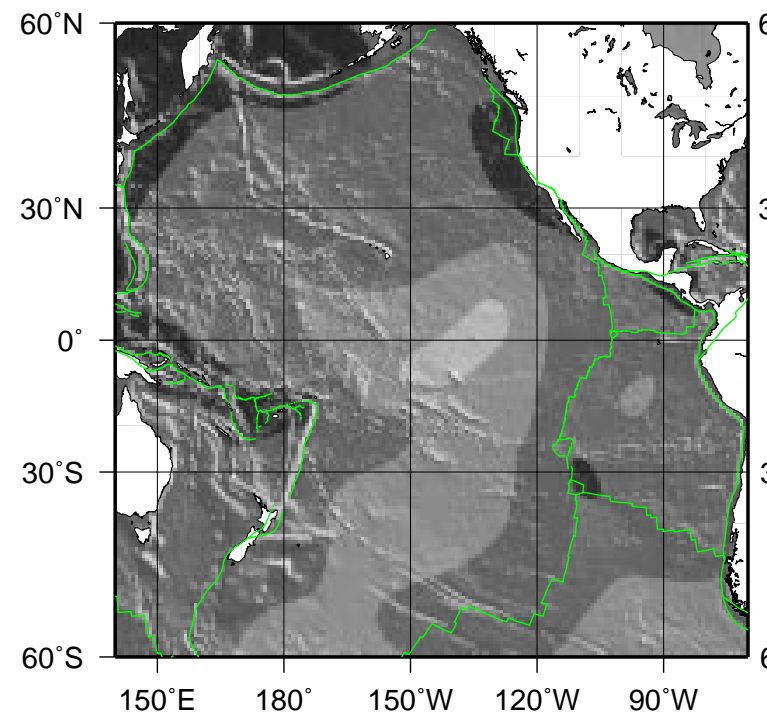

(b)

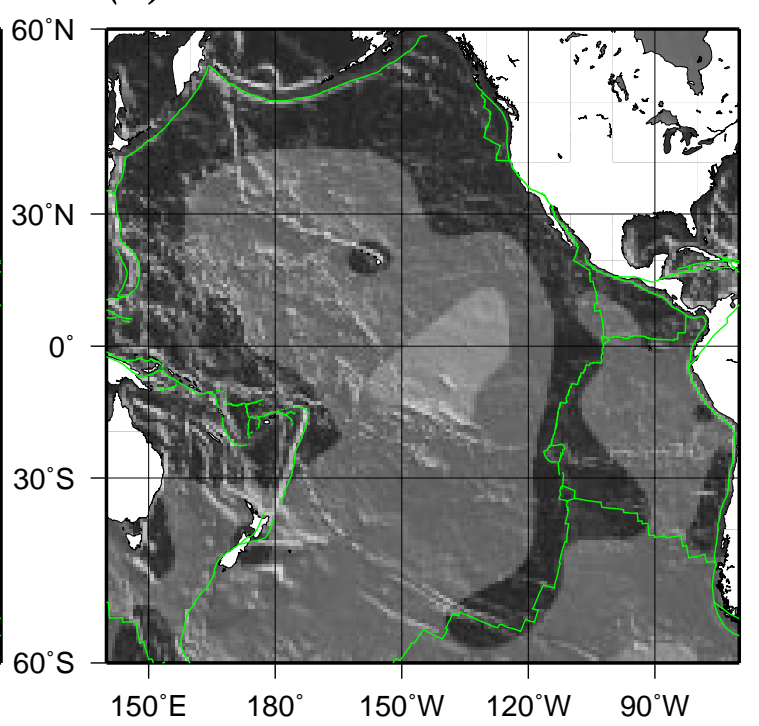

(d)

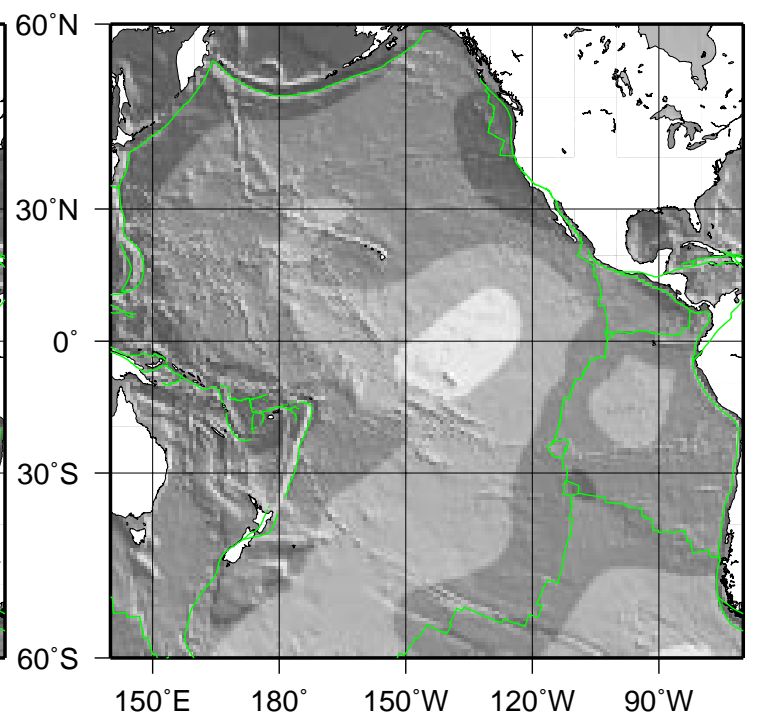

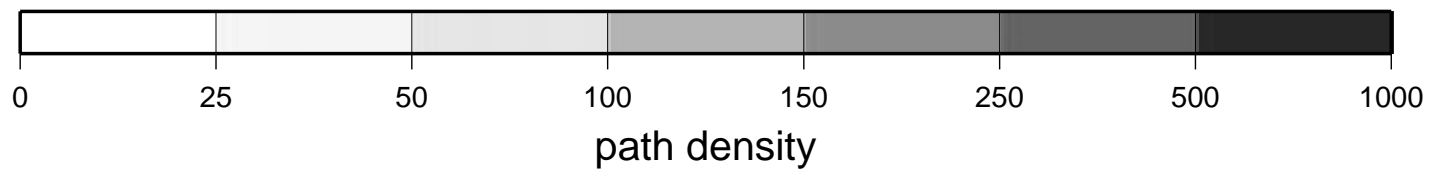

Figure 2: Path density across the Pacific. Path density for oceanic areas centered on the Pacific for the (a) $20 \mathrm{sec}$, (b) $50 \mathrm{sec}$, (c) $100 \mathrm{sec}$, and (d) $150 \mathrm{sec}$ Rayleigh wave group velocity measurements. Path density is defined as the number of measurement paths intersecting each $2^{\circ} \times 2^{\circ}$ cell $\left(\sim 50,000 \mathrm{~km}^{2}\right)$. Green lines denote plate boundaries. 
(a)

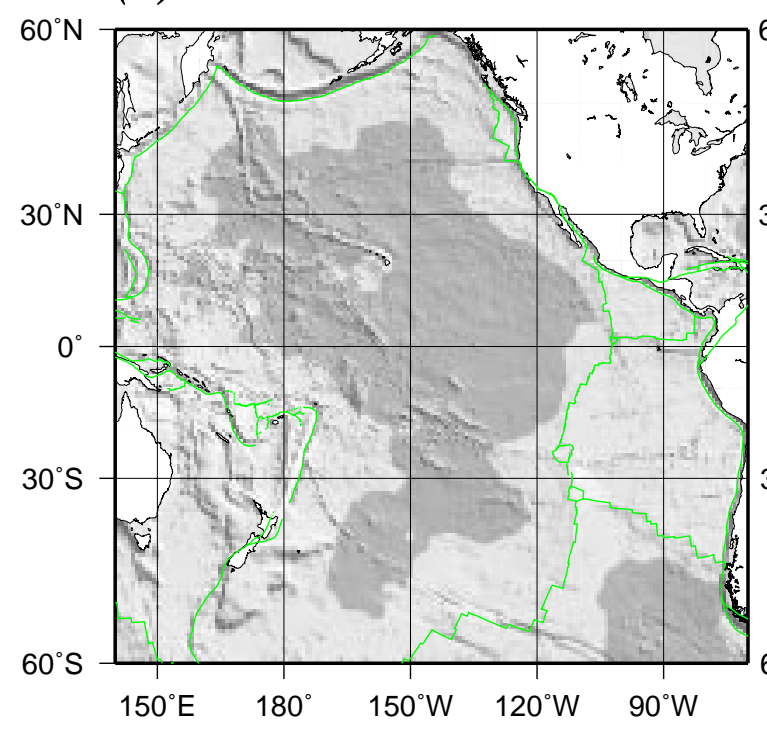

(c)

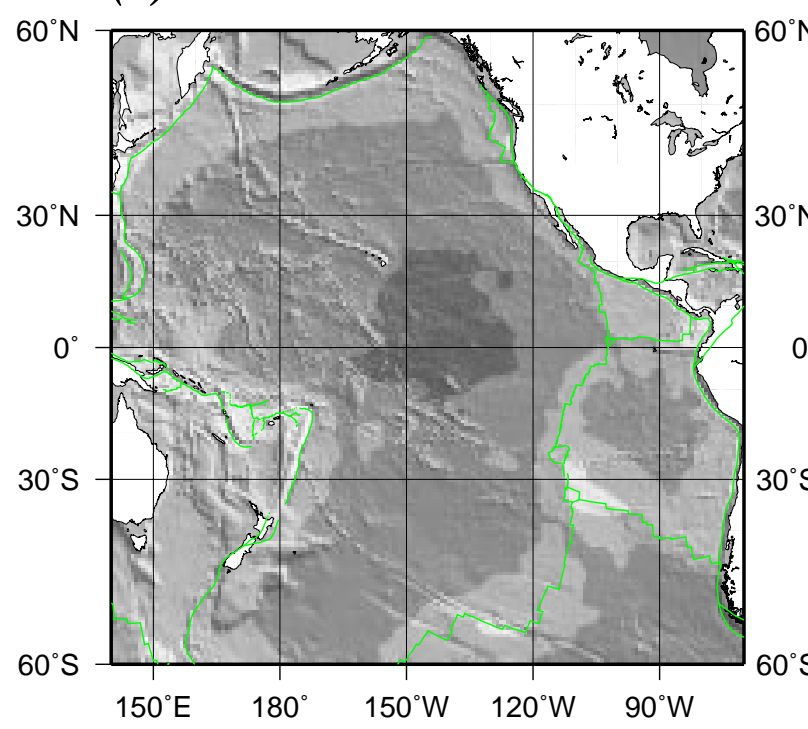

(b)

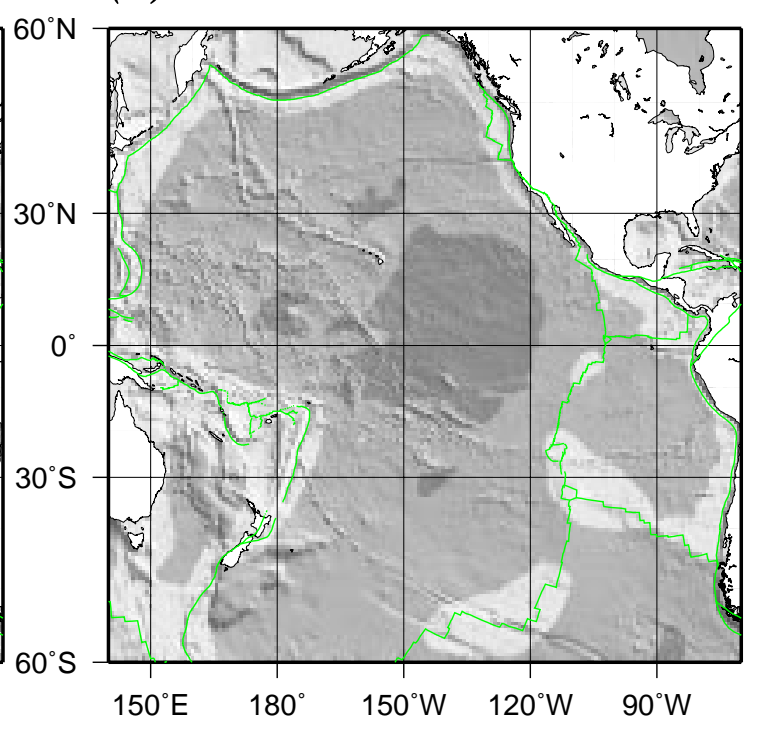

(d)
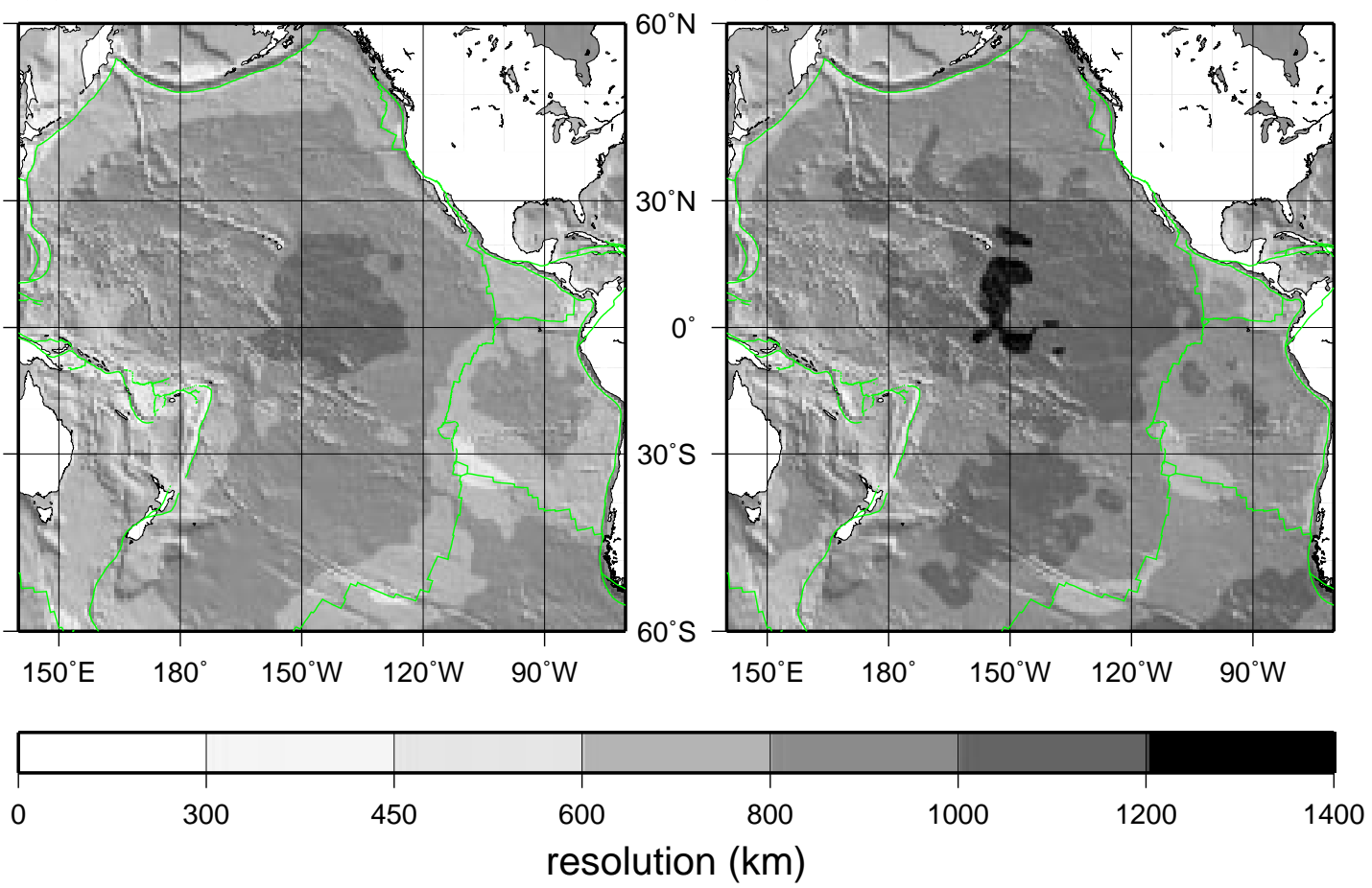

Figure 3: Resolution estimates across the Pacific. Resolution is estimated as twice the standard deviation of a surface Gaussian fit to the resolution surface at each point. Results here are for Rayleigh wave group velocities at periods of (a) $20 \mathrm{sec}$, (b) $50 \mathrm{sec}$, (c) $100 \mathrm{sec}$, and (d) $150 \mathrm{sec}$. Green lines denote plate boundaries. 


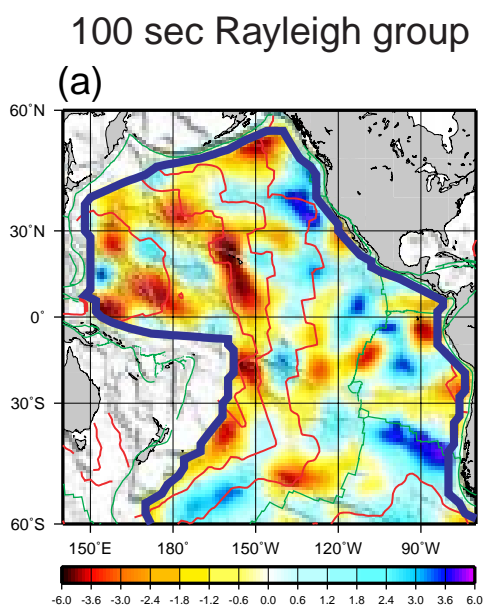

perturbation to the HSC model (\%) (d)

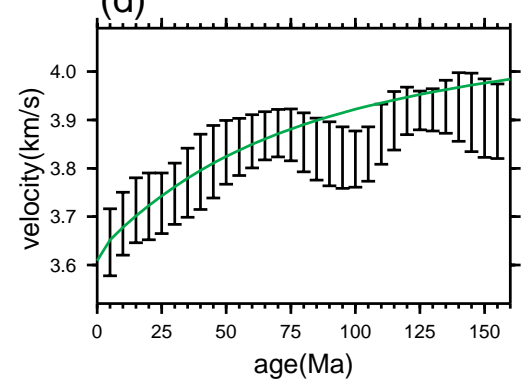

50 sec Rayleigh phase

(b)

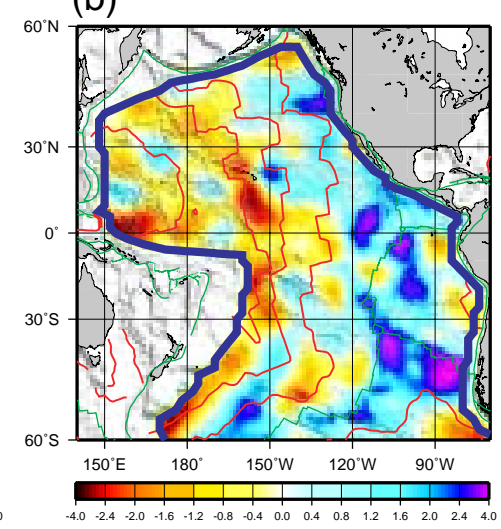

perturbation to the HSC model (\%)

(e)

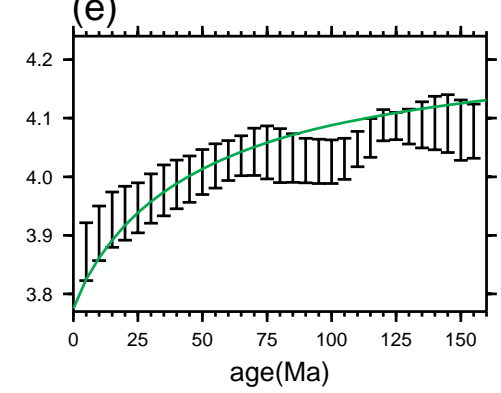

$50 \mathrm{sec}$ Love group

(c)

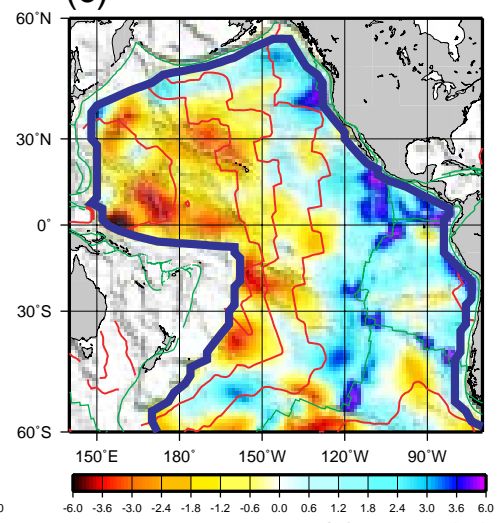

perturbation to the HSC model (\%)

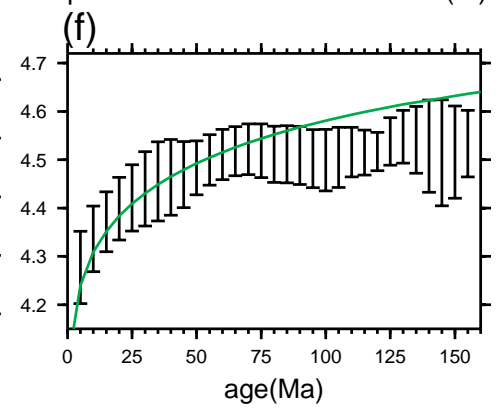

Figure 4: Surface wave speed maps and trends with lithospheric age. (a) - (c) Maps of surface wave speed plotted as a percent perturbation to the speed predicted from the HSC model (green lines in (d) - (f)) for $100 \mathrm{sec}$ Rayleigh wave group speed, $50 \mathrm{sec}$ Rayleigh wave phase speed, and $50 \mathrm{sec}$ Love wave group speed, respectively. The green lines denote plate boundaries, the red lines are isochrons of lithospheric age in increments of $35 \mathrm{Ma}$, and the blue contour encloses the region where there are lithospheric age estimates (40). (d) - (f) Surface wave speed, averaged in 5 Ma lithospheric age bins across the Pacific, is plotted versus lithospheric age for the maps in (a) - (c), respectively. "Error" bars represent the standard deviation within each age range. Predictions from the HSC model in (a) - (f) are shifted to fit the observations optimally between $10 \mathrm{Ma}$ and $60 \mathrm{Ma}:-70 \mathrm{~m} / \mathrm{s}$ in (a) \& (d), $-80 \mathrm{~m} / \mathrm{s}$ in (b) \& (e), and $10 \mathrm{~m} / \mathrm{s}$ in (c) \& (f). This shift accommodates radial anisotropy and arbitrary choices in the definition of the HSC model (e.g., initial mantle temperature). 
(a)

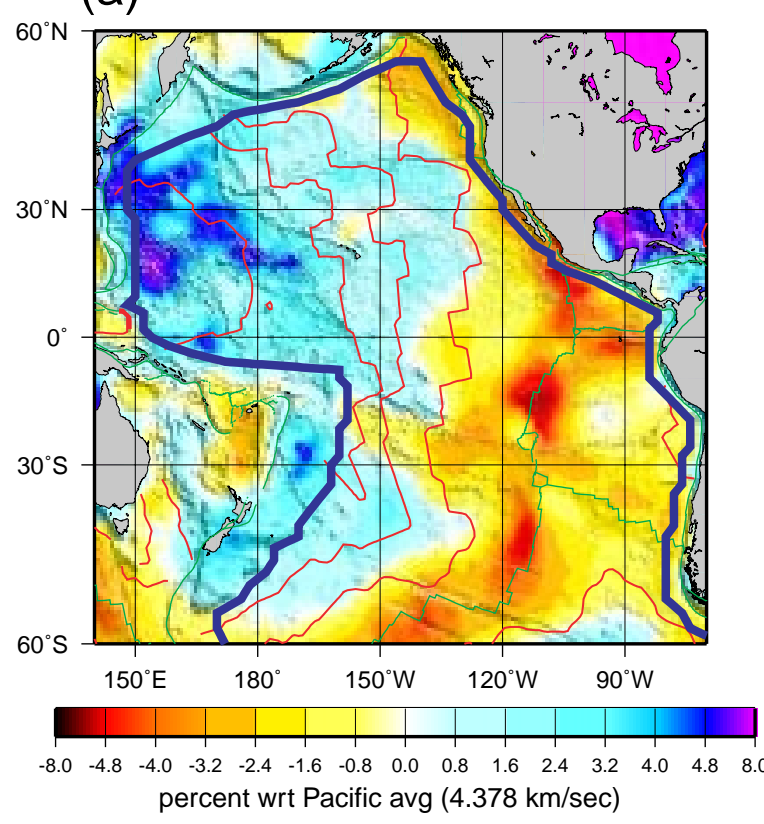

(b)

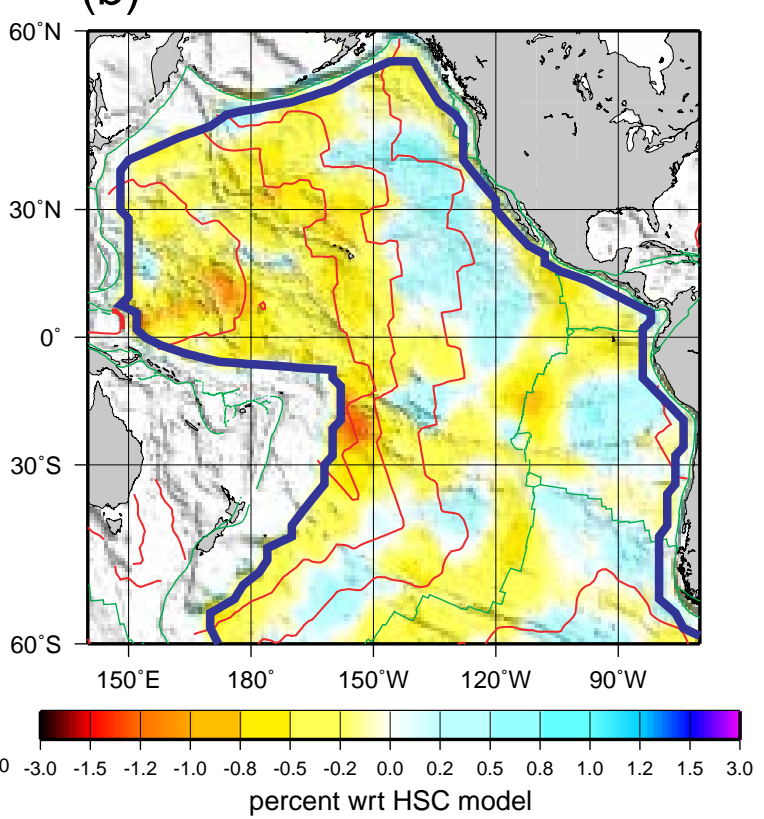

(c)

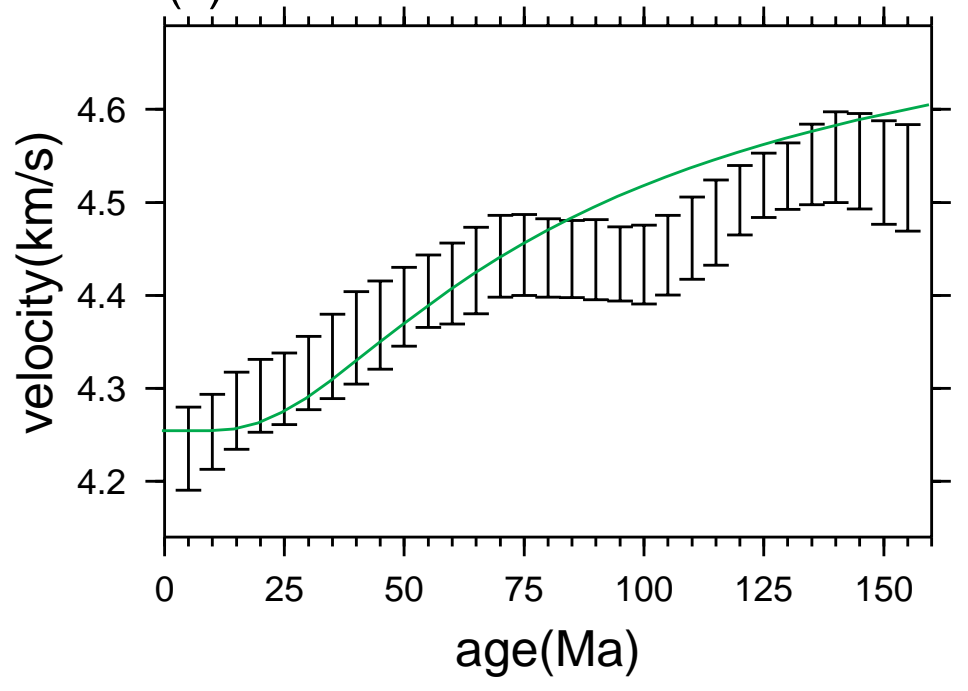

Figure 5: Shear velocity structure of the Pacific upper mantle using the seismic parameteriza-

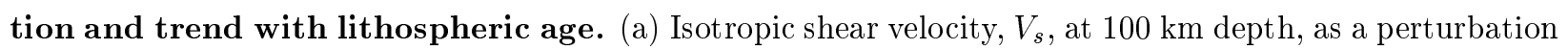
to the average at this depth across the Pacific $(4.378 \mathrm{~km} / \mathrm{sec})$. The green lines denote plate boundaries, the red lines are isochrons of lithospheric age in increments of $35 \mathrm{Ma}$, and the blue contour encloses the region where there are lithospheric age estimates (40). (b) $V_{s}$ at $100 \mathrm{~km}$ depth presented as a perturbation to the prediction from the HSC model. (c) Shear velocity, averaged in 5 Ma lithospheric age bins across the Pacific, is plotted versus lithospheric age at $100 \mathrm{~km}$ depth. "Error" bars represent the standard deviation within each age range. The continuous green line is the prediction from the HSC model shifted vertically by -30 $\mathrm{m} / \mathrm{s}$. 
(a)

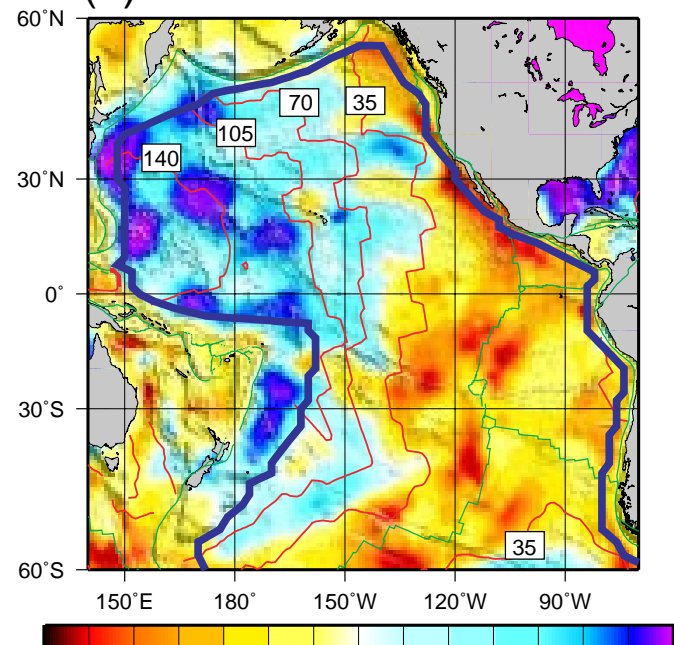

$\begin{array}{lllllllllllllllll}-8.0 & -4.8 & -4.0 & -3.2 & -2.4 & -1.6 & -0.8 & 0.0 & 0.8 & 1.6 & 2.4 & 3.2 & 4.0 & 4.8 & 8.0\end{array}$ perturbation to Pacific average (\%)

(c)

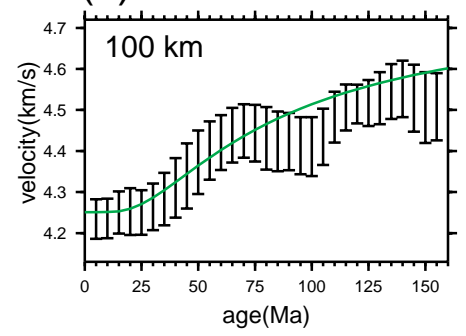

(d)

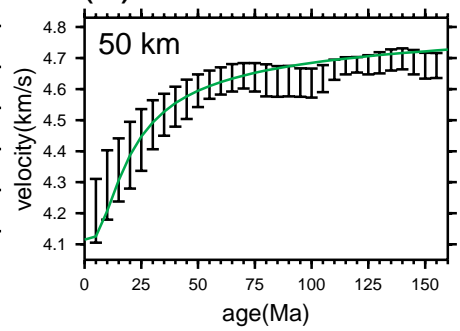

(b)

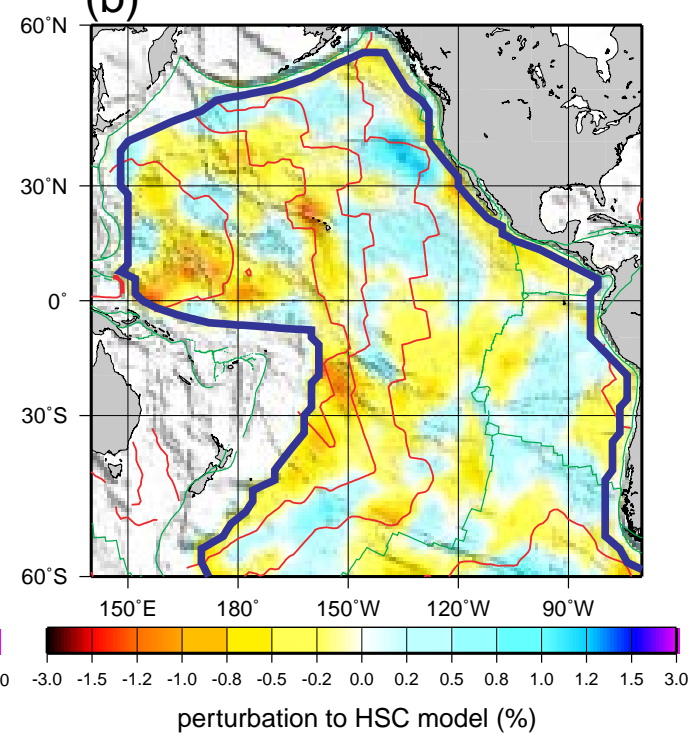

(e)

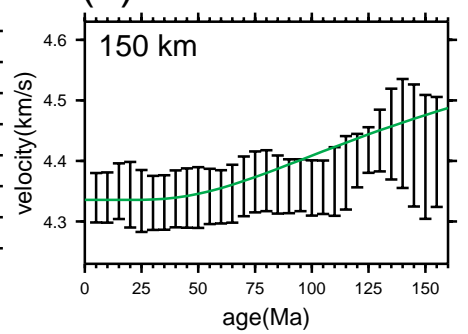

Figure 6: Shear velocity structure of the Pacific upper mantle and trend with lithospheric age using the thermal parameterization: Horizontal slices. (a) Shear velocity at $100 \mathrm{~km}$ depth, presented as a perturbation to the average across the Pacific $(4.362 \mathrm{~km} / \mathrm{sec})$. The green, red, and blue lines are as in Figure 5a-c. (b) Shear velocity at $100 \mathrm{~km}$ depth presented as a perturbation to the prediction from the HSC model. (c) - (e) Shear velocity, averaged in 5 Ma lithospheric age bins across the Pacific, is plotted versus lithospheric age at $100 \mathrm{~km}, 50 \mathrm{~km}$, and $150 \mathrm{~km}$ depths. "Error" bars represent the standard deviation within each age range. The continuous green lines are the predictions from the HSC model shifted vertically to fit the observations optimally between $10 \mathrm{Ma}$ and $60 \mathrm{Ma}:-30 \mathrm{~m} / \mathrm{s}$ at $100 \mathrm{~km},-10 \mathrm{~m} / \mathrm{s}$ at $50 \mathrm{~km}$, and $-70 \mathrm{~m} / \mathrm{s}$ at $150 \mathrm{~km}$. This figure should be contrasted with the model derived using the seismic parameterization in Figure 5 . 
(a)

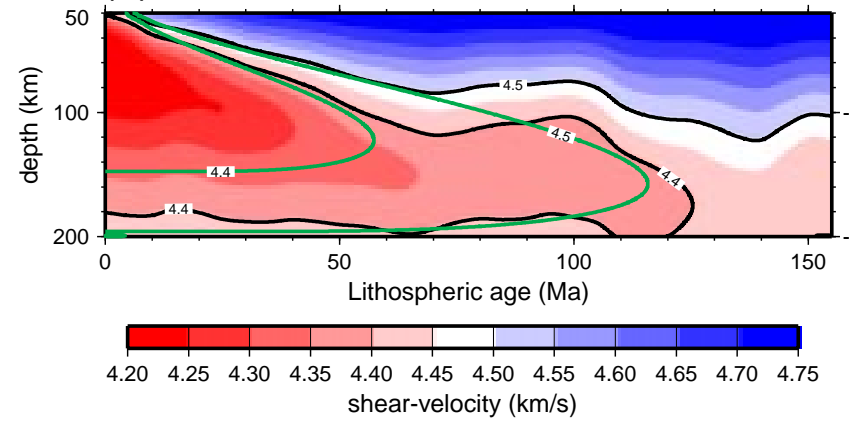

(b)

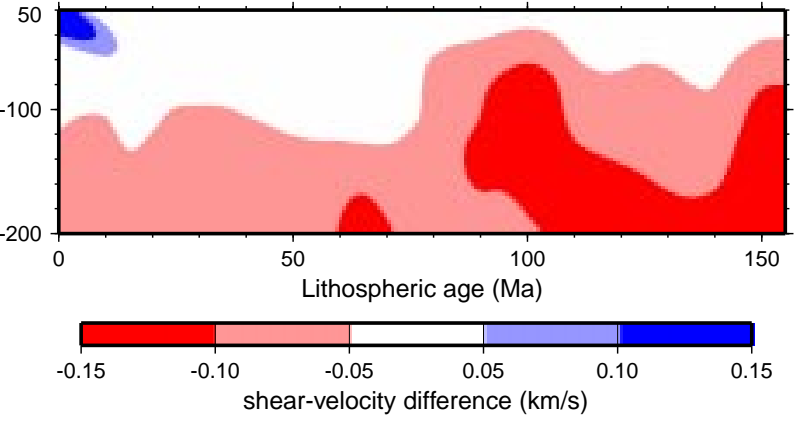

Figure 7: Shear velocity structure of the Pacific upper mantle and trend with lithospheric age using the thermal parameterization: Vertical profile. (a) $V_{s}$ averaged across the Pacific plotted versus lithospheric age. The green lines are isotachs (lines of constant shear velocity) from the HSC model. (b) Difference between the Pacific average shear velocity and the prediction from the HSC model. Reds identify areas where the observed shear velocity is slower than the HSC model predicts. 
(a)

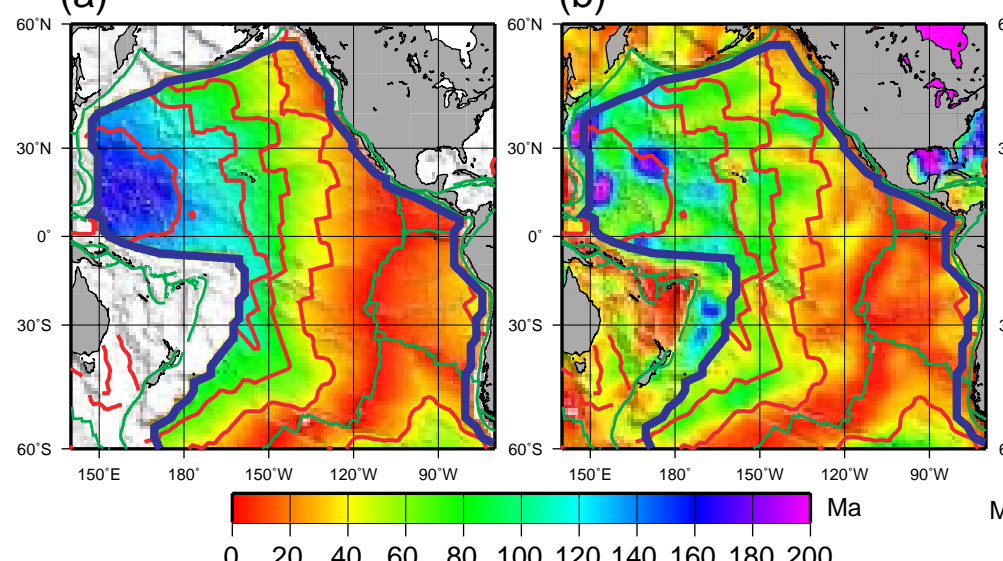

(d)

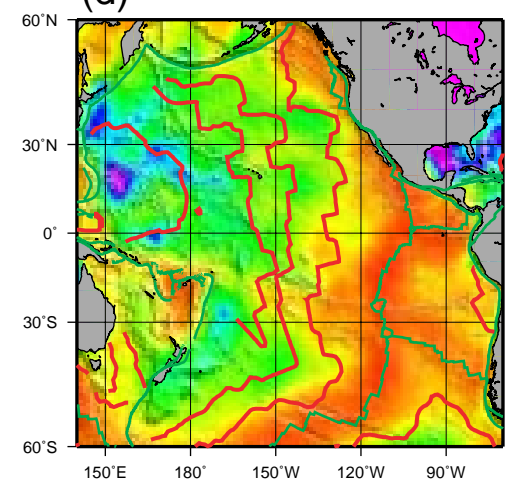

(c)

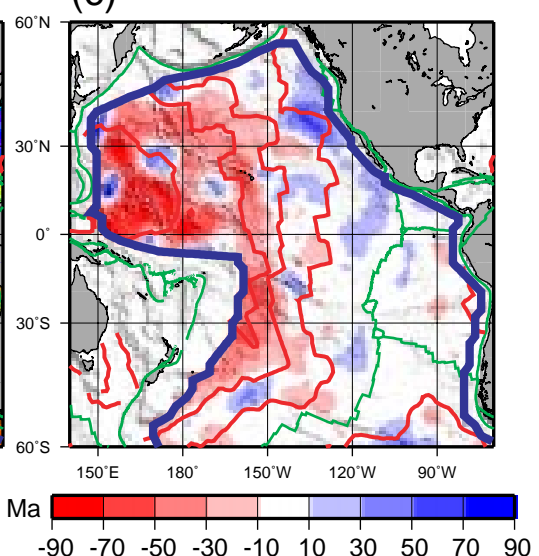

(e)

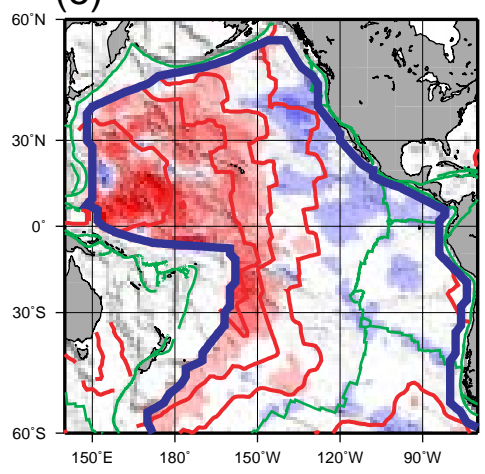

Figure 8: Apparent thermal age of the Pacific upper mantle estimated with the thermal and seismic parameterizations. (a) Lithospheric age in Ma, presented as a reference (40). (b) Apparent thermal age, $\tau$, estimated using the thermal parameterization. (c) Difference between the lithospheric age and the apparent thermal age in (b). Reds imply that the apparent thermal age is younger than the lithospheric age. (d) Apparent thermal age estimated using the seismic parameterization. (e) Difference between the lithospheric age and the apparent thermal age in (d). 
(a)

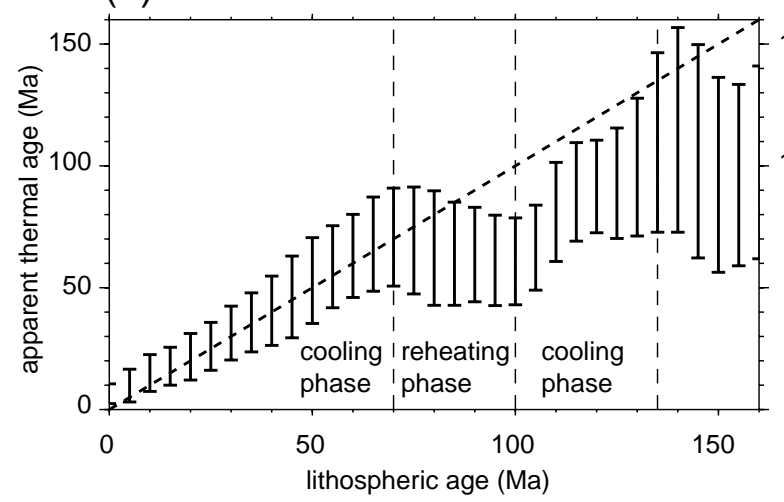

(b)

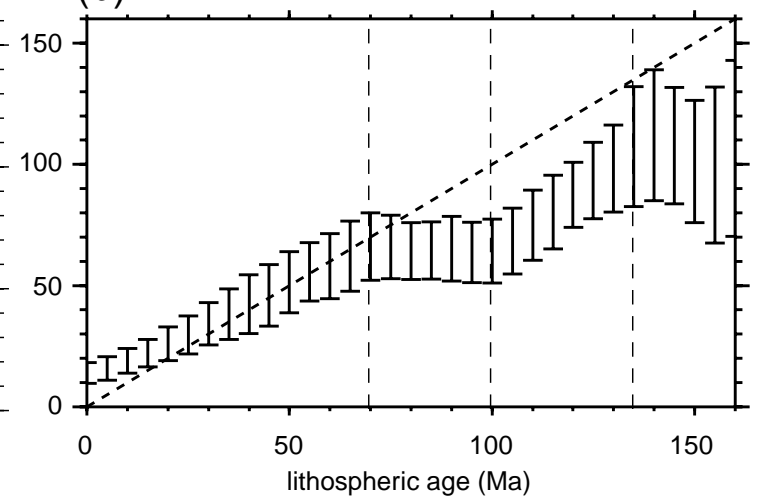

Figure 9: Apparent thermal age of the Pacific upper mantle from the thermal and seismic parameterizations aggregated versus lithospheric age. (a) The "error" bars represent the standard deviation of $\tau$ within each 5 Ma lithospheric age bin averaged across the Pacific estimated with the thermal parameterization. Two lithospheric cooling phases are identified, 0 - $70 \mathrm{Ma}$ and 100 - $135 \mathrm{Ma}$, bracketing a phase in which the Pacific lithosphere undergoes reheating. (b) Same as (a), but $\tau$ is estimated with the seismic parameterization.
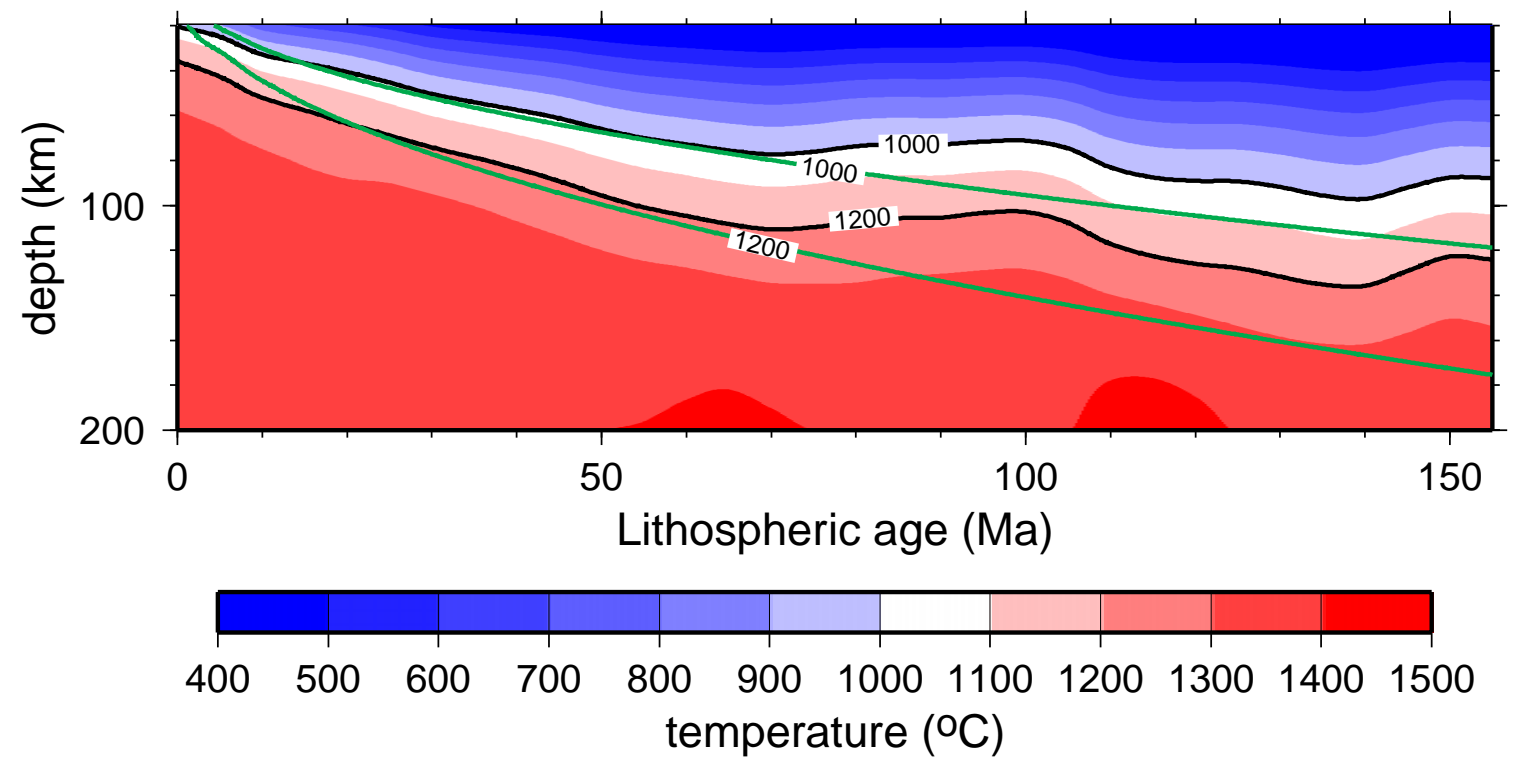

Figure 10: Average temperature profile of the Pacific upper mantle versus lithospheric age. Upper mantle temperature from the inversion based on the temperature parameterization averaged across the Pacific plotted versus lithospheric age. The green lines are isotherms from the HSC model. An average perturbation of more than $100^{\circ} \mathrm{C}$ develops between the observed and HSC temperature profiles at a depth of about $100 \mathrm{~km}$ due to processes of reheating that occur between 70 and $100 \mathrm{Ma}$ in the Central Pacific. 


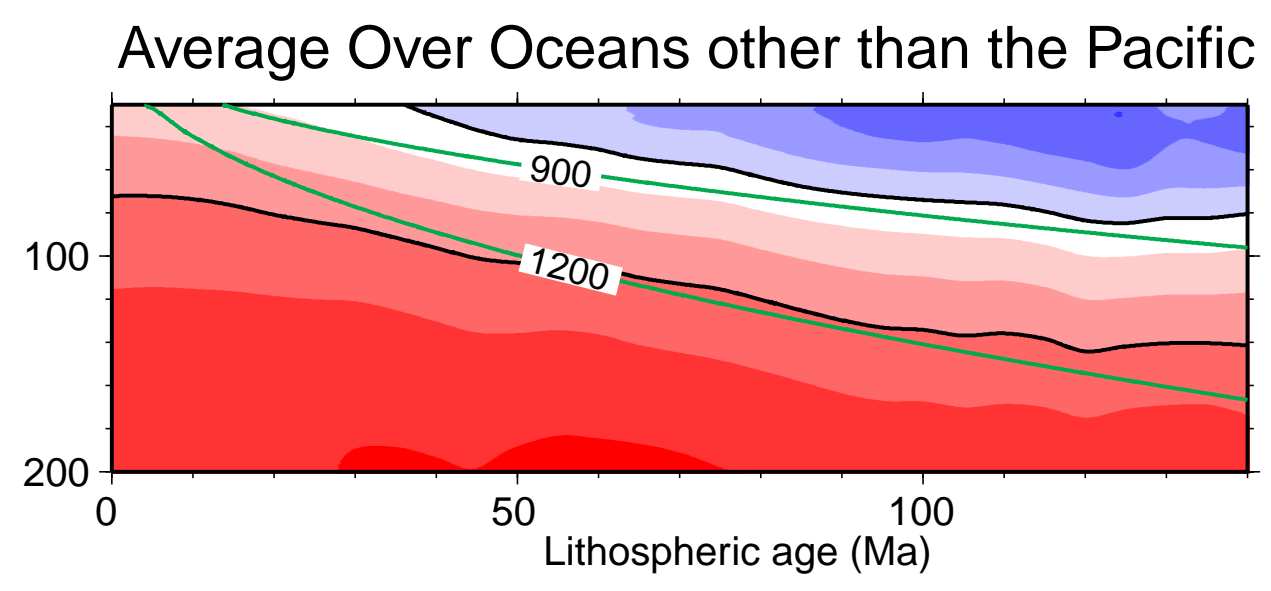

Figure 11: Temperature in oceans other than the Pacific. Upper mantle temperature averaged across all oceans other than the Pacific, plotted versus lithospheric age. Contrast Figure 10. The green lines are isotherms from the HSC model.
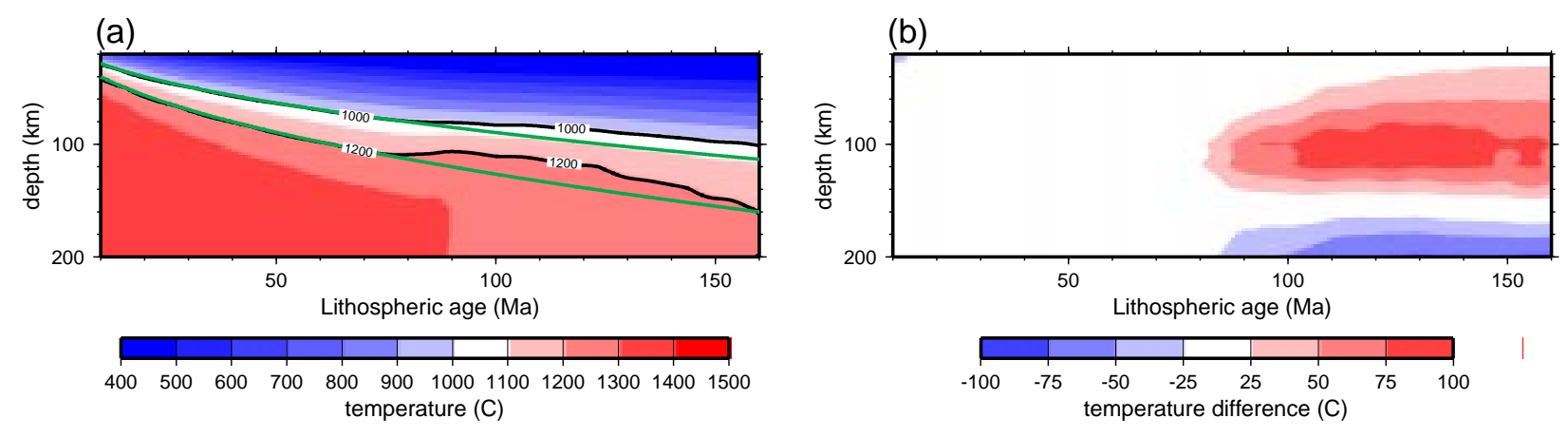

Figure 12: Thermal structure versus lithospheric age for the simulation of TBI. (a) Temperatures from the 3-D convection simulation of thermal boundary layer instabilities are averaged parallel to the ridge at each depth and plotted versus lithospheric age. The green lines are isotherms from the HSC model. (b) The difference between the temperatures from the simulation of TBI with the HSC model. Reds imply that temperatures in TBI simulation are warmer than in the HSC model. 


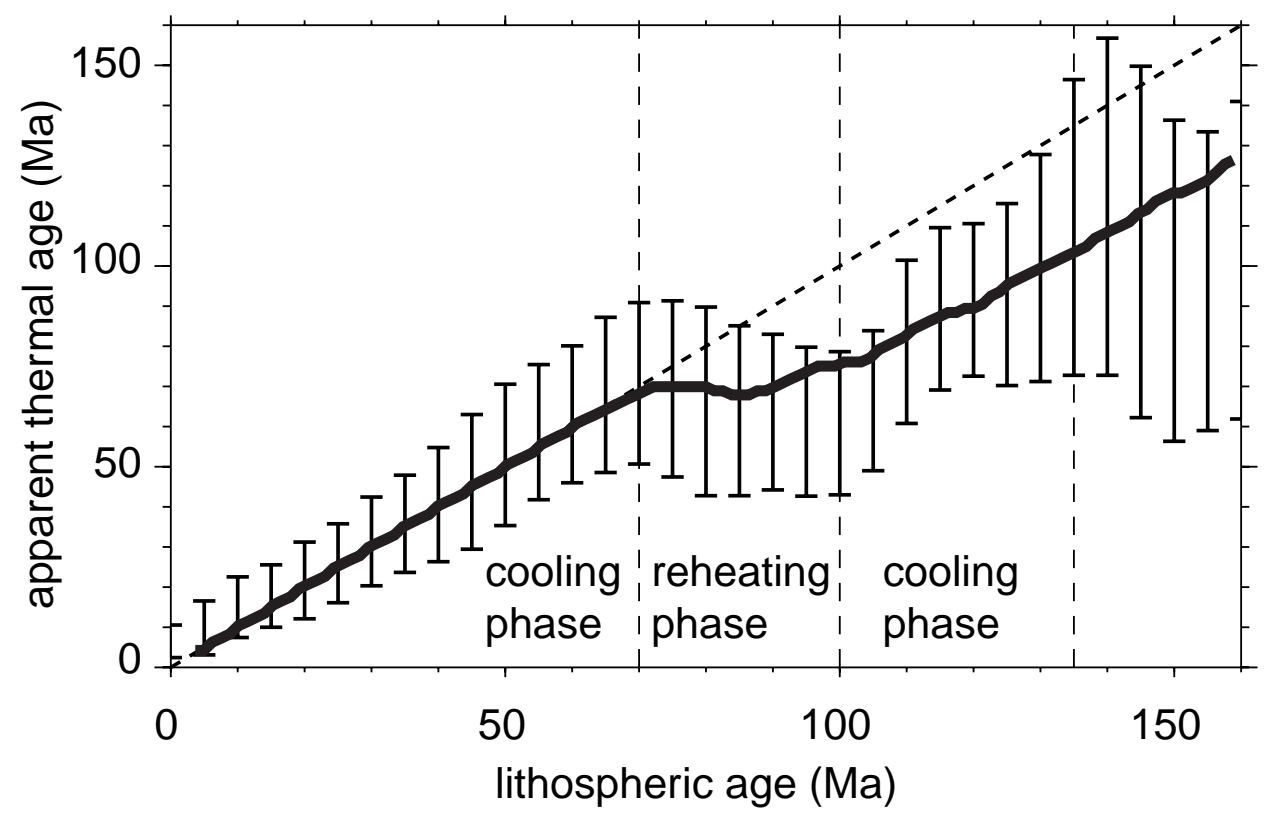

Figure 13: Simulation of TBI expressed as apparent thermal age versus lithospheric age. Similar to Figure 9a, except the thick black line is $\tau$, averaged in lithospheric age bins, computed from the 3-D convection model of thermal boundary layer instabilities, with an effective rheological activation energy of $120 \mathrm{~kJ} / \mathrm{mol}$. 